\title{
Causality Assessment of Adverse Drug Reaction Using Naranjo Probability Scale: A Retrospective Study
}

\section{Sangha Ratna Bajracharya ${ }^{1}$, Rakesh Ghimire ${ }^{1}$, Pradip Gyanwali ${ }^{1}$ and Anjan Khadka ${ }^{2}$}

${ }^{1}$ Department of Clinical Pharmacology, Institute of Medicine, Tribhuvan University Teaching Hospital, Maharajgunj, Kathmandu, Nepal

${ }^{2}$ Department of Pharmacology, Nepalese Army Institute of Health Sciences, Sanobharyang, Kathmandu, Nepal

\begin{abstract}
Introduction: Globally, Adverse Drug Reaction (ADR) has been listed as the sixth leading causes of death. Recognition of ADR and establishment of relationship of drug with the symptom is the first step to the management of the problem. In this study, Naranjo algorithm has been used which is one of the most accepted tools for the assessment of causality of ADR with the suspected drug.

Methods: A retrospective descriptive study was done which included 35 reported cases of ADRs in Drug Information Unit (DIU) in tertiary care teaching institute of Nepal from Dec 2015 to Oct 2016. Based on the information in the reported ADRs forms, categorisation was done using Naranjo's ADR Probability scale. The data was analysed using SPSS version 16.0 and descriptive statistics was used.

Results: It was seen that ADRs were more common in male $(n=20)$ as compared to female $(n=15)$. Amongst male, ADRs were more common in age group 50-75 years $(\mathrm{n}=8)$. ADRs were most commonly seen with antimicrobial agents (40\%) followed by Non-Steroidal Anti-inflammatory Drugs (NSAIDs) (20\%) and immunosuppressants (20\%). Within the antimicrobial agents, anti-tubercular drugs $(20 \%)$ contributed the most in ADRs and hepatotoxicity was the most common ADR seen. Majority of ADRs were categorised under possible $(n=29)$ followed by probable $(n=6)$.
\end{abstract}

Conclusions: Naranjo algorithm could be a useful tool for causality assessment of ADR which can help physicians to guide the therapy.

Key words: adverse drug reaction; causality; Naranjo algorithm

Correspondence: Sangha Ratna Bajracharya, Department of Clinical Pharmacology, Institute of Medicine, Tribhuvan University Teaching Hospital, Maharajgunj, Kathmandu, Nepal. E-mail:sanghab@hotmail.com.

DOI: http://dx.doi.org/10.3126/mjsbh.v19i1.21573

Submitted on: 2018-11-02

Accepted on: 2019-12-12 


\section{INTRODUCTION}

World Health Organisation (WHO) definition of Adverse Drug Reactions (ADR) is any response to a drug that is noxious and unintended and which occurs at doses normally used in man for prophylaxis, diagnosis or therapy of diseases or for the modification of physiological function. Causality assessment is used to evaluate the relationship between the occurrence of the adverse event and the drug used during the treatment. Multiple drugs are usually used for the treatment of the patients and results in difficulty to identify an ADR in daily practice. ${ }^{1}$

ADRs is one of the major global health problem resulting in the economic burden for the healthcare systems and considered to be the sixth leading cause of death. ${ }^{2}$ Allergies, toxicities, and side effects are the examples of the adverse reactions that can occur after drug use. Recognition of ADRs and Causality assessment play an important role in better management of the adverse reactions. Different tools are developed to categorise ADRs that help to confirm the probability of ADRs. To evaluate the probability of true ADRs from suspected ADRs, Naranjo et al. has proposed a tool and has been widely used as Naranjo Algorithm.

Uppsala Monitoring Centre is WHO collaborating centre for International Drug Monitoring which works by collecting, assessing and communicating information from member countries' national pharmacovigilance centres in regard to the benefits, harm, effectiveness, and risks of drugs. Department of Drug Administration (DDA) is a National Pharmacovigilance Centres in Nepal. Our institute is one of the regional centres to report ADRs to DDA. The present study was carried out to evaluate the probability of true ADRs from suspected ADRs by using Naranjo Algorithm and to improve the scientific basis of causality assessment before it is sent to National Pharmacovigilance Centre.

\section{METHODS}

This was a retrospective descriptive study. All cases of ADRs from different wards by different drugs reported to Drug Information Unit (DIU) from Dec
2015 to Oct 2016 were obtained. Based on the information in the reported ADRs form, categorisation was done using Naranjo's ADR Probability scale. ${ }^{3}$ This probability scale evaluates the causality of ADRs and categorise them as definite, probable, possible and doubtful.

Total number of 35 reported cases of ADRs were evaluated. Along with thorough drug history, records of preliminary information, detailed history regarding presenting symptoms, intensity and duration was reviewed and considered. Drugs causing ADR were grouped in different categories and this category was further grouped in the different drug subcategories. The data was analysed using SPSS 16 version and descriptive statistics was used in the form of frequency and tables.

\section{RESULTS}

There were total number of 35 reported cases of ADRs in Drug Information Unit (DIU), TUTH which is one of the regional pharmacovigilance centres of Nepal. It was seen that ADRs were more common in males $(n=20)$ as compared to females $(n=15)$. ADRs were more in males of age between 50 to 75 years $(n=8)$ (Table 1$)$.

Antimicrobial drugs were found to have more ADRs followed by NSAIDs and immunosuppressants. The different drug groups and incidence of ADR is shown in Table 2. Among antimicrobials, the most ADRs were seen with antitubercular drugs (20\%), antibiotics (14.3\%) and antivirals (5.7\%). The most common ADR observed in our study was hepatotoxicity which was seen with isoniazid $(42.8 \%)$, rifampicin (28.5\%), vancomycin (14.2\%) and lamivudine

Table 1: Age and sex wise distribution of ADRs

\begin{tabular}{|l|r|r|r|r|}
\hline Age categories & Male & Female & Total & Percentage \\
\hline 0-25 years & 1 & 0 & 1 & $2.85 \%$ \\
\hline 25-50 years & 5 & 5 & 10 & $28.57 \%$ \\
\hline $51-75$ years & 8 & 4 & 12 & $34.29 \%$ \\
\hline Above 75 years & 6 & 6 & 12 & $34.29 \%$ \\
\hline & 20 & 15 & 35 & \\
\hline
\end{tabular}


Table 2. Different drug categories responsible for ADRs

\begin{tabular}{|l|r|}
\hline Drug Categories & Percentage \\
\hline Antimicrobial & $40.0 \%$ \\
\hline NSAIDs & $20 \%$ \\
\hline Immunosuppressant & $20 \%$ \\
\hline Cardiovascular System drugs & $11.4 \%$ \\
\hline Central Nervous System drugs & $5.7 \%$ \\
\hline Others & $2.9 \%$ \\
\hline
\end{tabular}

(14.2\%). Causality assessment of reported ADRs was done by using Naranjo scale (Table 3).

\section{DISCUSSION}

There are various methods to determine causation of ADRs. Naranjo's causality assessment is one of them which is used to determine the likelihood of a drug that caused a suspected ADR. Our study showed male preponderance over females in ADRs which is similar to the study done by Bista et al. ${ }^{3}$ Highest numbers of ADRs were seen in the patient age more than 50 years that showed $68.58 \%$. The previous study showed higher percentage of ADRs in age group 21 to 40 years $^{4}$ and in age group 19 to 59 years. $^{5}$ However, our study showed $28.57 \%$ ADRs in age group 25 to 50 years.

This study reported that antimicrobial agents were responsible for majority $40 \%$ of ADRs followed by NSAIDs, immunosupressants and cardiovascular drugs. Among antimicrobials, antitubercular drugs $20 \%$ was found to be major drug to cause ADRs followed by antibiotics which is similar to study carried out by Yee et al. ${ }^{6}$ This observation suggests that the decision on the use of antitubercular drugs to the patient should be evaluated before prescribing. However, similar studies have shown antibiotics as the most common to cause ADRs. ${ }^{4,7}$ Hepatotoxicity was the most common ADRs, among which Isoniazid was found to be the commonest drug. This study re-established that the use of anti-tubercular drugs and antibiotics requires ruling out preexisting hepatic dysfunction and completing liver function evaluation prior to its use. Increase incidence of ADRs with
Table 3. Causality assessment of reported ADRs

\begin{tabular}{|l|l|r|r|}
\hline \multicolumn{1}{|l|}{ Score } & Severity & Number & Percentage \\
\hline 0 & Doubtful & 0 & $0 \%$ \\
\hline $1-4$ & Possible & 29 & $82.86 \%$ \\
\hline $5-8$ & Probable & 6 & $17.14 \%$ \\
\hline$>8$ & Definite & 0 & $0 \%$ \\
\hline
\end{tabular}

antimicrobials might be due to the fact that there is increase antimicrobial prescription in our settings. The prevalence of ADRs with antimicrobials agents in our study was similar to the study conducted by Moore et al. and Tyagi et al. ${ }^{8,9}$

Using Naranjo algorithm, it was seen that majority of ADRs belong "possible" $\mathrm{n}=29 \quad(82.86 \%)$ followed by "probable" $n=6(17.14 \%)$. No ADRs were doubtful and definite. This could be due to small sample size. The use of Naranjo algorithm can help the treating physician to conclude that particular drug has caused an ADR and guide the therapy to reduce ADR. It is common among clinician due to its simplicity in use. Causality assessment aid regulatory authorities in evaluating ADRs and risk-benefit decisions about medicines. 10,11 Causality assessment algorithms are organised frameworks that help in objective decision making on causality. ${ }^{12}$ Causality assessment should be recommended and performed widely once ADR monitoring is intensified in all health care institute by educating and motivating healthcare providers to report ADRs. ${ }^{13}$

\section{LIMITATIONS}

The numbers of reported ADR were small in number. Since this study is retrospective, inadequate patient's information have influenced the causality assessment of some ADRs.

\section{CONCLUSIONS}

The use of Naranjo algorithm can help the treating physician to conclude that particular drug has caused an ADR and guide the therapy. Pharmacovigilance system should be strengthened in Nepal with the active participation from regional centres and national centre to understand the 
prevalence of ADRs and training programs to

minimise it.

To cite this article: Bajracharya SR, Ghimire R, Gyanwali P, Khadka A. Causality assessment of adverse drug reaction using Naranjo Probability Scale: a retrospective study. MJSBH. 2019;19(1):16-9.

Conflict of Interest: None declared

\section{REFERENCES}

1. Requirements for adverse drug monitoring. Geneva, Switzerland: World Health Organisation; 1975.

2. Lazarou J, Pomeranz BH, Corey PN. Incidence of adverse drug reactions in hospitalised patients: A meta-analysis of prospective studies. JAMA. 1998;279:1200-5.

DOI: https://doi.org/10.1001/jama.279.15.1200

3. Naranjo CA, Busto U, Sellers EM, Sandor P, Ruiz I, Roberts EA, et al. A method for estimating the probability of adverse drug reactions. Clin Pharmacol Ther. 1981;30(2):239-45.

DOI: https://doi.org/10.1038/clpt.1981.154

4. Bista D, Shrestha BR, Rai P, Jauhari AC, Kulshrestha VK. Pattern of adverse drug reactions reported to the regional Pharmacovigilance center at Nepal Medical College and Teaching Hospital, Kathmandu. JNPA. 2012;26(1):54-61. DOI: https://doi.org/10.3126/jnpa.v26i1.6633

5. Jha N, Bajracharya O, Namgyal T. Prevalence of adverse drug reactions with commonly prescribed drugs in different hospitals of Kathmandu valley. KUMJ. 2007;5(4):504-10.

PMID: 18604084

6. Yee D, Valiquette C, Pelletier M, Parisien I, Rocher I, Menzies D. Incidence of serious side effects from first-line antituberculosis drugs among patients treated for active tuberculosis. Am J Respir Crit Care Med. 2003;167:14727.

DOI: https://doi.org/10.1164/rccm.200206-626OC

7. Palaian S, Ibrahim MIM, Mishra P. Pattern of adverse drug reactions reported by the community pharmacists in Nepal. Pharmacy Practice. 2010;8(3):201-7.

DOI: https://doi.org/10.4321/S1886-36552010000300008

8. Moore N, Lecointre D, Noblet C, Mabille M. Frequency and cost of serious adverse drug reactions in a department of general medicine. Br J Clin Pharmacol. 1998;45:301-8.

DOI: https://doi.org/10.1046/j.1365-2125.1998.00667.x

9. Tyagi N, Gulati K, Vijayan VK, Ray A. A study to monitor adverse drug reactions in patients of chronic obstructive pulmonary disease: Focus on theophylline. Indian J Chest Dis Allied Sci. 2008;50:199-202.

10. Macedo AF, Marques FB, Ribeiro CF, Teixeira F. Causality assessment of adverse drug reactions: Comparison of the results obtained from published decisional algorithms and from the evaluations of an expert panel. Pharmacoepidemiol Drug Saf. 2005;14:885-90.

DOI: https://doi.org/10.1002/pds.1138

11. Belhekar MN, Taur SR, Munshi RP. A study of agreement between the Naranjo algorithm and WHO-UMC criteria for causality assessment of adverse drug reactions. Indian J Pharmacol. 2014;46:117-20.

DOI: https://doi.org/10.4103/0253-7613.125192

12. Turner WM. The food and drug administration algorithm. Special workshop - Regulatory. Drug Inf J. 1984;18:259-66.

DOI: https://doi.org/10.1177/009286158401800311

13. Gupta SK, Kumar KD. An assessment of reported adverse drug reactions in a Tertiary Care Hospital in South India: A retrospective cross-sectional study. Int J Pharm Investig. 2017;7(4):193-7.

DOI: 10.4103/jphi.JPHI_81_17. 